\title{
The effect of anaesthesia on $\left[{ }^{18}\right.$ F]MK-9470 binding to the type 1 cannabinoid receptor in the rat brain
}

\author{
Cindy Casteels • Guy Bormans • Koen Van Laere
}

Received: 17 December 2009/Accepted: 5 January 2010 /Published online: 25 February 2010

(C) Springer-Verlag 2010

\begin{abstract}
Purpose Small animal PET can be applied to study molecular processes in animal models of a variety of human diseases. In order to keep the animals in a restricted position during imaging, anaesthesia is in many instances inevitable. Using small animal PET and ex vivo autoradiography, we examined the influence of pentobarbital and isoflurane anaesthesia on the rat brain uptake of $\left[{ }^{18} \mathrm{~F}\right] \mathrm{MK}$ 9470, a radioligand for the type 1 cannabinoid receptor.

Methods PET imaging was performed on adult Wistar rats under pentobarbital $(n=6)$ and isoflurane anaesthesia $(n=7)$, and under control conditions (free moving during tracer uptake, $n=8$ ). Parametric PET images were generated, anatomically standardized and analysed by voxel-based Statistical Parametric Mapping and a predefined volume of interest approach. Immediately after in vivo PET, brains were processed for ex vivo autoradiography using manually placed regions of interest. An extra group $(n=6)$ was included ex vivo, in which animals were intravenously injected without the use of anaesthetics.

Results Using in vivo and ex vivo molecular imaging techniques, no significant changes in absolute $\left[{ }^{18} \mathrm{~F}\right] \mathrm{MK}$ -
\end{abstract}

C. Casteels $(\bowtie) \cdot K$. Van Laere

Division of Nuclear Medicine, KU Leuven and University

Hospital Gasthuisberg,

Herestraat 49 bus 7003 ,

3000 Leuven, Belgium

e-mail: cindy.casteels@med.kuleuven.be

C. Casteels $\cdot$ G. Bormans $\cdot$ K. Van Laere

MoSAIC, Molecular Small Animal Imaging Center, KU Leuven,

Leuven, Belgium

G. Bormans

Laboratory for Radiopharmacy, KU Leuven,

Leuven, Belgium
9470 uptake were present in the brain of pentobarbital and isoflurane rats as compared to control conditions. Relative $\left[{ }^{18} \mathrm{~F}\right] \mathrm{MK}-9470$ uptake PET values obtained applying global scaling were, however, decreased in the cortex under both anaesthetics (pentobarbital: $-13.3 \pm 1.4 \%$; isoflurane $-8.7 \pm$ $3.1 \%$ ), while an increase was seen in the cerebellum by $13.5 \pm 4.0 \%$ and $13.9 \pm 4.1 \%$ under pentobarbital and isoflurane, respectively. Ex vivo results were in agreement with in vivo findings.

Conclusion These findings suggest a similar, regionally specific interference of pentobarbital and isoflurane anaesthesia with in vivo CB1 receptor imaging using $\left[{ }^{18} \mathrm{~F}\right] \mathrm{MK}-9470$.

Keywords $\left[{ }^{18} \mathrm{~F}\right] \mathrm{MK}-9470$ - Type 1 cannabinoid receptor . Anaesthesia $\cdot$ Ex vivo autoradiography $\cdot$ Small animal PET

\section{Introduction}

The endocannabinoid system (ECS) consists of cannabinoid receptors, endogenous ligands, of which anandamide (AEA) and 2-arachidonoylglycerol (2-AG) are the bestcharacterized substances, and of proteins for their biosynthesis and degradation [1]. Converging evidence points towards an important role of the ECS in homeostatic mechanisms of the brain and in pathophysiological conditions such as epilepsy, addiction, stroke, eating disorders, schizophrenia and movement disorders [2]. This broad-spectrum action occurs through modulating the release, uptake and actions of excitatory and inhibitory transmitters such as $\gamma$ aminobutyric acid (GABA), glutamate and dopamine [3] and has potential for pharmacological treatments [4].

Therapeutic approaches can be assessed non-invasively using functional small animal PET imaging. However, in 
order to prevent movement artefacts, animals must be either physically restrained or placed under anaesthesia [5]. Anaesthesia is known to have significant effects on the central nervous, cardiovascular and respiratory systems [5] and, therefore, differences in radioligand uptake and regional binding in the brain may occur. The effects of anaesthesia are not predictable since changes are often of different magnitude and direction amongst target receptor, enzyme or transporter systems [6, 7]. They may vary for structurally unrelated radioligands for a specific binding site and be inconsistent among different classes of anaesthetic agents $[8,9]$.

The mechanism of pentobarbital and isoflurane, two commonly used anaesthetics for small animal PET imaging, involves interaction with multiple receptor sites, and thereby interference with synaptic transmission [3]. Pentobarbital, as a barbiturate, is believed to potentiate the effect of GABA through the $\mathrm{GABA}_{\mathrm{A}}$ receptor [10], while isoflurane binds both to GABA receptors [11] and glutamate receptors [12] and increases extracellular dopamine concentration through interference with dopamine transporter (DAT) expression [13].

Recently, a novel ${ }^{18}$ F-labelled, high affinity, subtypeselective radioligand for type 1 cannabinoid (CB1) receptor imaging, $\left[{ }^{18} \mathrm{~F}\right] \mathrm{MK}-9470$, was developed [14]. We investigated the potential influence of pentobarbital and isoflurane anaesthesia on $\left[{ }^{18} \mathrm{~F}\right] \mathrm{MK}-9470$ uptake in the rat brain using both quantitative in vivo small animal PET and ex vivo autoradiography.

\section{Materials and methods}

Animals and anaesthesia

Experiments were conducted on 27 adult female Wistar rats. Animal weight was $236 \pm 19 \mathrm{~g}$ (range: $182-269 \mathrm{~g}$ ) and animal age $12.3 \pm 1.2$ weeks (range: 9-14 weeks). All animals were housed three to a cage, at an average room temperature of $22^{\circ} \mathrm{C}$ and a 12 -h light/dark cycle (lights on at 8 a.m.). Food and water were given ad libitum. The research protocol was approved by the local Animal Ethics Committee and was according to European Ethics Committee guidelines (decree 86/609/EEC).

The effect of anaesthesia on rat brain $\left[{ }^{18} \mathrm{~F}\right] \mathrm{MK}-9470$ uptake was quantified using both small animal PET and ex vivo autoradiography. The influence of anaesthesia on rat brain $\left[{ }^{18} \mathrm{~F}\right] \mathrm{MK}-9470$ uptake was assessed in vivo under three conditions: (1) in free moving animals during tracer uptake, as controls $(n=8)$; (2) using $2 \%$ isoflurane (Halocarbon, River Edge, NJ, USA) and $100 \% \mathrm{O}_{2}$ inhalation through a nose cone $(n=7)$; and (3) after an intraperitoneal injection of $50 \mathrm{mg} / \mathrm{kg}$ pentobarbital $(n=6)$
(Nembutal, CEVA Santé Animale, Brussels, Belgium). Immediately after in vivo PET, brains were processed for ex vivo autoradiography. For ex vivo analysis, an extra condition (4) was included, in which animals $(n=6)$ were free moving during tracer uptake, but also unanaesthetized during injection (hereafter referred to as 'awake').

\section{Small animal PET}

Small animal PET image acquisitions were performed after overnight fasting. The rat tail veins were catheterized to enable the infusion of $\left[{ }^{18} \mathrm{~F}\right] \mathrm{MK}-9470$ (injected dose: $47.5 \pm$ $7.7 \mathrm{MBq}$; specific activity range: $53-541 \mathrm{GBq} / \mu \mathrm{mol}$; injection volume: $500 \mu \mathrm{l})$. Sixty-minute dynamic $\left[{ }^{18} \mathrm{~F}\right]$ MK-9470 acquisitions were started immediately after tracer injection ( $\sim 5 \mathrm{~min}$ after sedation) for the animals assigned to the pentobarbital and isoflurane groups. Animals which were free moving during tracer uptake were also briefly ( $\sim \mathrm{min})$ sedated with $2 \%$ isoflurane for tracer injection. Free moving animals were scanned during 20 min starting $40 \mathrm{~min}$ post-injection under isoflurane anaesthesia. The acquisition timing rationale and kinetics of $\left[{ }^{18} \mathrm{~F}\right] \mathrm{MK}-9470$ in rats have been described previously [15].

Small animal PET imaging was performed using a FOCUS 220 tomograph (Siemens/Concorde Microsystems, Knoxville, TN, USA), which has a transaxial resolution of $1.35 \mathrm{~mm}$ full-width at half-maximum. Data were acquired in a $128 \times 128 \times 95$ matrix with a pixel width of $0.475 \mathrm{~mm}$ and a slice thickness of $0.796 \mathrm{~mm}$.

The precursor for $\left[{ }^{18} \mathrm{~F}\right] \mathrm{MK}-9470$ was obtained from Merck Research Laboratories (MRL, West Point, PA, USA). Radiolabelling was performed on-site by alkylation of the precursor with $2-\left[{ }^{18} \mathrm{~F}\right]$ fluoroethylbromide, as described previously [14].

Ex vivo autoradiography

Immediately after in vivo imaging, the animals were decapitated. Animals assigned to the awake group (condition 4) were sacrificed 60 min post-injection by cervical dislocation. All brains were quickly and carefully removed, frozen by immersion in cold 2-methylbutane in dry ice and immediately processed for sectioning. Coronal sections 20$\mu \mathrm{m}$ thick were cut in a cryostat (Thermo Fisher Scientific, Zellik, Belgium). Sections were thaw-mounted on Superfrost Plus ${ }^{\circledR}$ microscope slides (Menzel-Gläser, Braunschweig, Germany) and autoradiographed on phosphor screens in standard film cassettes. The phosphor screens were placed against a standard radiology light box immediately before use to erase any background radiation that may have been detected while in storage.

After overnight exposure at room temperature, the screens were removed from the cassettes under dim lighting 
and immediately scanned at 600 dpi resolution using a Cyclone Storage Phosphor System (Packard Instrument Co., Meriden, CT, USA).

Data analysis

PET scans were reconstructed using filtered backprojection and the last $20 \mathrm{~min}$ of each acquisition period were used for quantification purposes. Parametric images based on standardized uptake values [SUV: activity concentration $(\mathrm{MBq} / \mathrm{ml}) \times$ body mass $(\mathrm{g}) /$ injected dose $(\mathrm{MBq})]$ were generated as a measure of absolute $\left[{ }^{18} \mathrm{~F}\right] \mathrm{MK}-9470$ uptake [14]. No significant differences in weight or injected activity were present between anaesthetized and free moving rats. We investigated absolute as well as relative uptake. Relative $\left[{ }^{18} \mathrm{~F}\right] \mathrm{MK}-9470$ uptake was expressed as SUV values normalized on whole-brain SUV.

For each subject, PET images were spatially normalized to a stereotactic space based on the rat brain Paxinos atlas [16]. Data were analysed on a voxel basis using SPM2 (Statistical Parametric Mapping) as well as a templatebased predefined volume of interest (VOI) approach.

SPM analysis was carried out using a categorical subject design (conditions: anaesthetics vs free moving) on parametric $\left[{ }^{18} \mathrm{~F}\right] \mathrm{MK}-9470$ images. Spatially normalized images were masked to remove extracerebral signals that would disrupt the global normalization. All images were smoothed with an isotropic Gaussian kernel of $1.2 \mathrm{~mm}$. Only significant clusters ( $p<0.05$, corrected for multiple comparisons) were retained, in combination with sufficient localizing power ( $p_{\text {height }}<0.005$, uncorrected for multiple comparisons), as described previously [17]. The extent threshold $\mathrm{k}_{\mathrm{E}}$ was 200 voxels $\left(1.6 \mathrm{~mm}^{3}\right)$. For analysis of relative $\left[{ }^{18} \mathrm{~F}\right] \mathrm{MK}-9470$ uptake, proportional scaling was used.

For VOI analysis, a predefined VOI map was loaded on all parametric images to permit calculation of average
SUVs within each VOI (PMOD, version 2.65, PMOD Inc., Zurich, Switzerland). As reported previously [16], this set of VOIs created in-house was defined according to the rat brain Paxinos atlas and represents the major cortical and subcortical structures of the rat brain (i.e. the caudateputamen, globus pallidus, nucleus accumbens, cerebellum, cerebral cortex, thalamus, hippocampus and pons).

The autoradiographic images of the rat brain were analysed using Optiquant v5.00 (PerkinElmer Inc., Zaventem, Belgium). $\left[{ }^{18} \mathrm{~F}\right] \mathrm{MK}-9470$ uptake was determined in the following regions, all characterized by high to moderate CB1 receptor availability [18]: cortex (frontal, dorsal and ventral part), caudate-putamen, hippocampus (anterior and posterior part), pons and cerebellum. For each region of interest (ROI), one circular ROI (2-8 $\left.\mathrm{mm}^{2}\right)$ was placed per hemisphere on three adjacent sections. A background ROI of the same area was placed adjacent to each slide to obtain background-corrected uptake values. Identification of anatomical structures was guided by the Paxinos stereotactic rat brain atlas [19]. The placement of ROIs was standardized for a particular area and was consistent across all sections (Fig. 1). The amount of $\left[{ }^{18} \mathrm{~F}\right] \mathrm{MK}-9470$ uptake in each ROI was measured in digital light units (DLU) per area $\left(\mathrm{mm}^{2}\right)$ and normalized on injected activity and whole-slice uptake for absolute and relative uptake values, respectively. Final values were obtained by averaging three autoradiograms. The linearity between DLU and radioactivity had been established prior to study set-up in the count range of $4.10^{-3}$ MBq-0.7 MBq $\left(y=582062 x+36284 ; \mathrm{R}^{2}=0.99\right)$.

\section{Conventional statistics}

Reported values are given as the mean $\pm \mathrm{SD}$. For comparison of $\left[{ }^{18} \mathrm{~F}\right] \mathrm{MK}-9470$ uptake in the rat brain among the different conditions, one-way analysis of variance (ANOVA) followed by two-sided Dunnett post hoc test

Fig. 1 Representative coronal (anterior to posterior) $\left[{ }^{18} \mathrm{~F}\right] \mathrm{MK}$ 9470 autoradiographic images of brain sections of a control rat showing the ROIs on $\mathrm{Fr} C x$ frontal cortex, $D C x$ dorsal cortex, $V C x$ ventral cortex, $C p u$ caudate-putamen, Ant $\mathrm{HC}$ anterior hippocampus, Post HC posterior hippocampus, $\mathrm{Cbl}$ cerebellum. Coloured bar expresses DLU/mm²

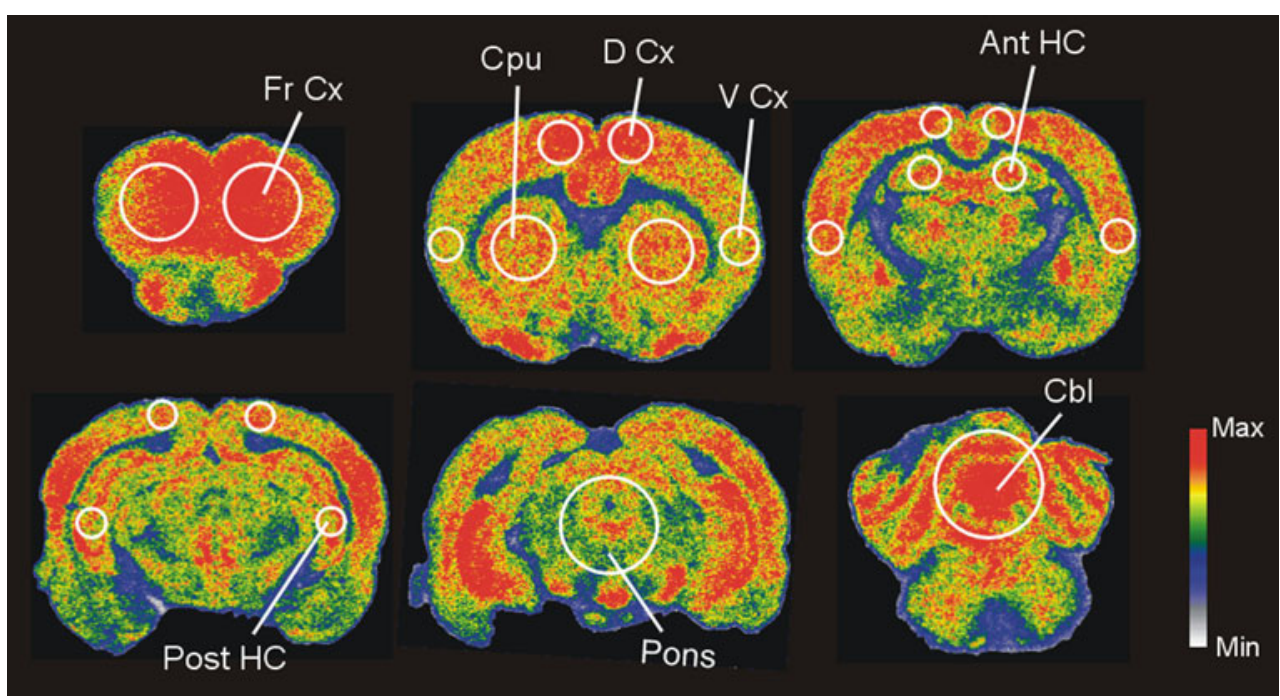




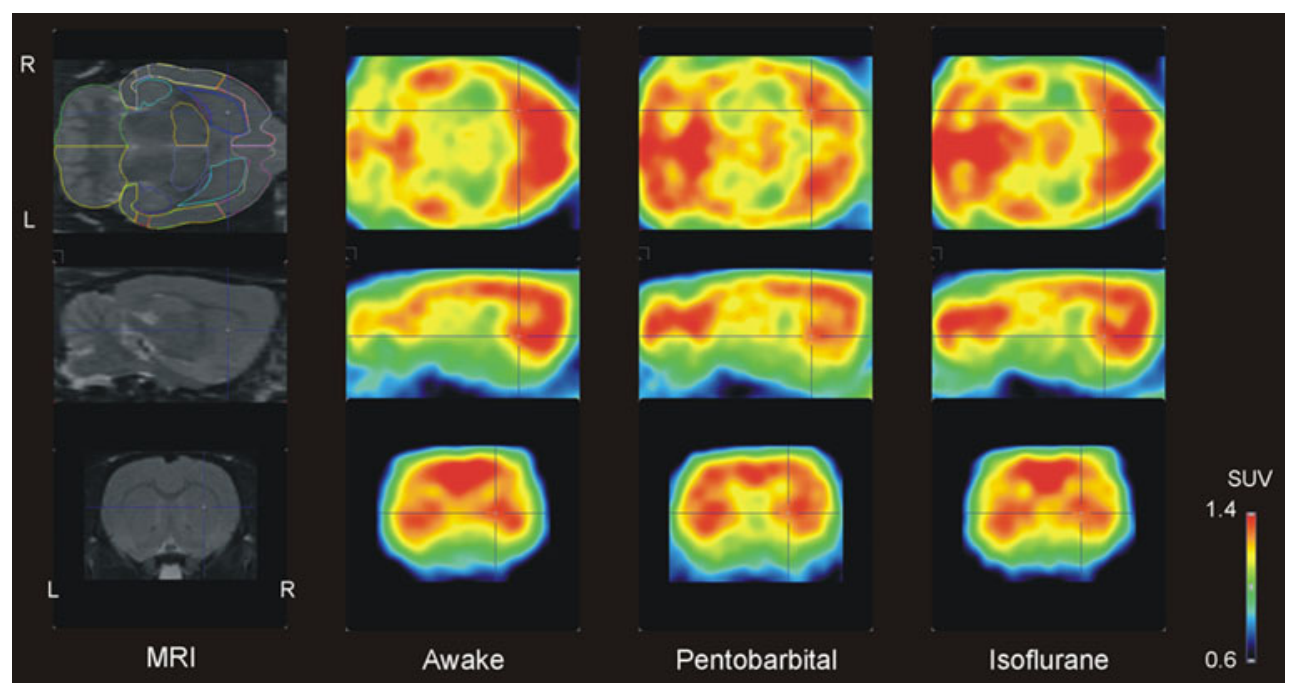

Fig. 2 Average cross-sectional small animal PET images, coregistered to MRI, of absolute $\left[{ }^{18} \mathrm{~F}\right] \mathrm{MK}-9470$ uptake in free moving and anaesthetized rats. Colour scale in SUV. The intersection points of the three planes have been set to the mid-striatal level [i.e. $(\mathrm{x}, \mathrm{y}, \mathrm{z})=$ $(-2.9,-0.3,-5.6)$ Paxinos coordinates], which corresponds to the

was performed on VOI and autoradiographic values. Significance was defined at the $95 \%$ probability level.

\section{Results}

\section{Small animal PET}

Representative images of absolute $\left[{ }^{18} \mathrm{~F}\right] \mathrm{MK}-9470$ uptake in the rat brain of free moving control animals and anaesthetized rats are shown in Fig. 2. right hemisphere ( $L$ left, $R$ right). The predefined VOI map is shown on the axial MRI image. Although no statistically significant difference was reached, an increase in absolute $\left[{ }^{18} \mathrm{~F}\right] \mathrm{MK}-9470$ uptake of anaesthetized rats as compared to free moving animals was observed in the cerebellum

Absolute $\left[{ }^{18} \mathrm{~F}\right] \mathrm{MK}-9470$ uptake was not significantly different in the brain of pentobarbital and isoflurane rats as compared to controls. The cortical uptake in controls was on average $1.22 \pm 0.13$, whereas under pentobarbital and isoflurane $1.23 \pm 0.10$ and $1.20 \pm 0.08$ was seen, respectively.

Relative $\left[{ }^{18} \mathrm{~F}\right] \mathrm{MK}-9470$ uptake maps showed a significantly lower CB1 receptor uptake in the cortex under anaesthesia (all $p \leq 1.510^{-6}$ ). The intensity of this reduction using the voxel-based approach was $-13.3 \pm 1.4 \%$ and $-8.7 \pm 3.1 \%$ for pentobarbital and isoflurane rats, respectively. The cortical reduction under both anaesthetics
Fig. 3 Per cent change in relative $\left[{ }^{18} \mathrm{~F}\right] \mathrm{MK}-9470$ uptake determined by VOI analysis in rats under pentobarbital (black bars) or isoflurane (grey bars) anaesthesia as compared to free moving animals. All data are shown as the mean $\pm \mathrm{SD}$. ${ }^{*} p<0.001 ; \# p<0.05$; one-way ANOVA followed by two-sided Dunnett post hoc test. $\mathrm{Cpu}$ caudate putamen, $N c$ Acc nucleus accumbens, $L G P$ lateral globus pallidus, $M G P$ medial globus pallidus, $\mathrm{Cbl}$ cerebellum, Thal thalamus, $H C$ hippocampus, $C x$ cortex, $\operatorname{Fr} C x$ frontal cortex, $S M C x$ sensorimotor cortex, $T L C x$ temporal lateral cortex, $T M C x$ temporal medial cortex

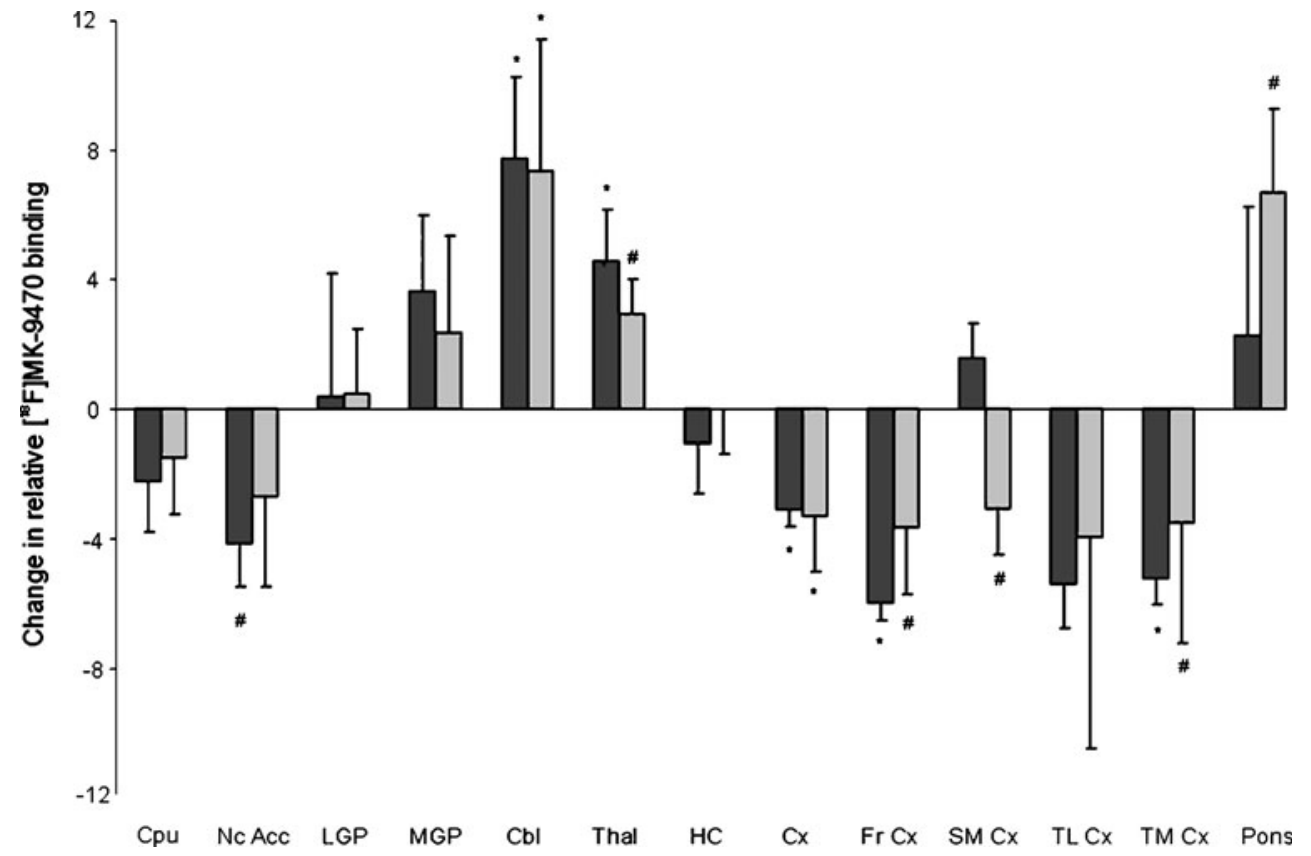


encompassed mainly the frontal association cortex, the medial, lateral and ventral orbital cortex, primary and secondary sensorimotor cortex, insular and cingulate cortex. For pentobarbital, relative $\left[{ }^{18} \mathrm{~F}\right] \mathrm{MK}-9470$ uptake was additionally decreased bilaterally in the entorhinal cortex (cluster peak value $-9.6 \% ; p=1.4 \quad 10^{-6}$ ) and hippocampus (cluster peak value $-9.5 \% ; p=3.610^{-5}$ ). Increases in relative $\left[{ }^{18} \mathrm{~F}\right] \mathrm{MK}-9470$ uptake were observed in the cerebellum with $13.5 \pm 4.0 \%$ and $13.9 \pm 4.1 \%$ for pentobarbital and isoflurane, respectively (all $p \leq 9.510^{-7}$ ). Under isoflurane, regional increase in relative $\left[{ }^{18} \mathrm{~F}\right] \mathrm{MK}-$ 9470 uptake was also present in the pons (peak value
$+7.7 \% ; p=1.110^{-5}$ ) and medulla oblongata (peak value $+13.5 \% ; p=8.110^{-8}$ ). When animals were anaesthetized using pentobarbital the $\left[{ }^{18} \mathrm{~F}\right] \mathrm{MK}-9470$ uptake in the right thalamic nuclei was increased by $5.5 \pm 2.5 \%$ relative to control conditions $\left(p=7.910^{-5}\right)$. VOI-based analysis confirmed these findings (all $p$ values $<0.05$ post hoc corrected; Fig. 3). Detailed cluster peak locations and $p$ values of the voxel-based comparison of pentobarbital and isoflurane rats to control animals are given in Table 1 . Regional differences in relative $\left[{ }^{18} \mathrm{~F}\right] \mathrm{MK}-9470$ uptake between anaesthetized rats and controls are shown in Figs. 4 and 5.

Table 1 Peak locations for the clusters in the comparison of anaesthetized rats versus free moving animals (at $p_{\text {height }} \leq 0.005$ uncorrected, $\mathrm{k}_{\mathrm{E}}>200$ )

\begin{tabular}{|c|c|c|c|c|c|c|c|c|c|}
\hline & \multicolumn{2}{|c|}{ Cluster level } & \multicolumn{3}{|c|}{ Voxel level } & \multicolumn{3}{|c|}{ Structure } & \multirow[t]{2}{*}{ Name } \\
\hline & pcorr & $\mathrm{k}_{\mathrm{E}}$ & $\mathrm{T}$ & puncorr & Intensity difference $(\%)$ & $\mathrm{x}$ & $\mathrm{y}$ & $\mathrm{z}$ & \\
\hline \multicolumn{10}{|c|}{ Isoflurane (I) vs free moving (FM) } \\
\hline \multirow[t]{3}{*}{$\mathrm{I}>\mathrm{FM}$} & $<0.001$ & 36192 & $\begin{array}{l}8.23 \\
7.45\end{array}$ & $\begin{array}{l}<0.001 \\
<0.001\end{array}$ & +13.5 & $\begin{array}{l}2.0 \\
1.0\end{array}$ & $\begin{array}{l}-13.6 \\
-5.4\end{array}$ & $\begin{array}{l}-9.6 \\
-8.0\end{array}$ & Medulla oblongata \\
\hline & & & 7.34 & $<0.001$ & +13.9 & 1.8 & -12.6 & -5.8 & Cerebellum \\
\hline & & & 5.7 & $<0.001$ & +7.7 & -2.2 & -7.2 & -7.6 & Pons \\
\hline \multirow[t]{4}{*}{$\mathrm{I}<\mathrm{FM}$} & $<0.001$ & 14484 & $\begin{array}{l}6.67 \\
6.56\end{array}$ & $\begin{array}{l}<0.001 \\
<0.001\end{array}$ & -8.7 & $\begin{array}{l}1.8 \\
2.2\end{array}$ & $\begin{array}{l}4.0 \\
-2.8\end{array}$ & $\begin{array}{l}-4.4 \\
-2.4\end{array}$ & Orbital cortex \\
\hline & & & 6.35 & $\leq 0.001$ & & 2.5 & 3.5 & -5.2 & \\
\hline & 0.02 & 2192 & $\begin{array}{l}4.78 \\
4.41\end{array}$ & $\begin{array}{l}<0.001 \\
\leq 0.001\end{array}$ & -6.1 & $\begin{array}{l}-6.8 \\
-6.8\end{array}$ & $\begin{array}{l}-2.0 \\
-4.2\end{array}$ & $\begin{array}{l}-6.8 \\
-3.0\end{array}$ & Insular cortex \\
\hline & & & 4.09 & $\leq 0.004$ & & -6.8 & -2.6 & -4.4 & \\
\hline \multicolumn{10}{|c|}{ Pentobarbital (P) vs free moving (FM) } \\
\hline \multirow[t]{6}{*}{$\mathrm{P}>\mathrm{FM}$} & $<0.001$ & 10716 & $\begin{array}{l}6.90 \\
5.93\end{array}$ & $\begin{array}{l}<0.001 \\
<0.001\end{array}$ & +13.5 & $\begin{array}{l}2.0 \\
5.2\end{array}$ & $\begin{array}{l}-13.6 \\
-13.2\end{array}$ & $\begin{array}{l}-2.0 \\
-6.0\end{array}$ & Cerebellum \\
\hline & & & 4.90 & $<0.001$ & & 1.8 & -12.8 & -5.4 & \\
\hline & 0.003 & 3110 & $\begin{array}{l}5.24 \\
4.04\end{array}$ & $\begin{array}{l}<0.001 \\
<0.001\end{array}$ & +8.0 & $\begin{array}{l}-4.0 \\
-5.0\end{array}$ & $\begin{array}{l}-12.6 \\
-13.0\end{array}$ & $\begin{array}{l}-6.8 \\
-4.2\end{array}$ & Cerebellum \\
\hline & & & 3.08 & $\leq 0.003$ & & -3.0 & -10.4 & -5.2 & \\
\hline & 0.02 & 2094 & $\begin{array}{l}4.75 \\
4.21\end{array}$ & $\begin{array}{l}<0.001 \\
<0.001\end{array}$ & +5.5 & $\begin{array}{l}-0.4 \\
2.8\end{array}$ & $\begin{array}{l}-3.0 \\
-3.2\end{array}$ & $\begin{array}{l}-5.2 \\
-5.2\end{array}$ & Thalamic nuclei \\
\hline & & & 3.93 & $<0.001$ & & 2.4 & -4.4 & -5.4 & \\
\hline \multirow[t]{6}{*}{$\mathrm{P}<\mathrm{FM}$} & $<0.001$ & 25094 & $\begin{array}{l}9.99 \\
9.54\end{array}$ & $\begin{array}{l}<0.001 \\
<0.001\end{array}$ & -13.3 & $\begin{array}{l}-0.2 \\
1.8\end{array}$ & $\begin{array}{l}4.0 \\
3.8\end{array}$ & $\begin{array}{l}-4.2 \\
-4.8\end{array}$ & Orbital cortex \\
\hline & & & 9.34 & $<0.001$ & & 2.2 & 3.6 & -5.0 & \\
\hline & $<0.001$ & 6329 & $\begin{array}{l}6.71 \\
6.52\end{array}$ & $\begin{array}{l}<0.001 \\
<0.001\end{array}$ & -9.6 & $\begin{array}{l}6.6 \\
7.0\end{array}$ & $\begin{array}{l}-7.2 \\
-5.4\end{array}$ & $\begin{array}{l}-7.8 \\
-7.4\end{array}$ & Entorhinal cortex \\
\hline & & & 5.91 & $<0.001$ & & 5.4 & -8.0 & -7.8 & \\
\hline & 0.004 & 2799 & $\begin{array}{l}5.43 \\
5.26\end{array}$ & $\begin{array}{l}<0.001 \\
<0.001\end{array}$ & -9.5 & $\begin{array}{l}-5.4 \\
-6.2\end{array}$ & $\begin{array}{l}-6.8 \\
-7.4\end{array}$ & $\begin{array}{l}-6.8 \\
-7.0\end{array}$ & Hippocampus \\
\hline & & & 4.27 & $<0.001$ & & -5.2 & -6.8 & -5.2 & \\
\hline
\end{tabular}

Anatomical locations and abbreviations were taken from the Paxinos stereotactic atlas [19]. The x-coordinate corresponds to the distance (mm) lateral from the midline between the hemispheres and is positive for spots located on the right side; the y-coordinate indicates the position relative to Bregma with spots located anterior to Bregma being positive; finally, the z-coordinate denotes the dorsoventral position. For each cluster, local maxima more than $0.3 \mathrm{~mm}$ apart are shown as different rows

pcorr cluster-corrected $p$ value, $k_{E}$ cluster extent (voxels), $T$ peak voxel $t$ statistic, puncorr uncorrected height $p$ value 
Fig. 4 Coronal brain sections showing overlays on the regions with statistically significantly increased (red) and decreased (blue) relative $\left[{ }^{18} \mathrm{~F}\right] \mathrm{MK}-9470$ binding in the pentobarbital group $(n=6)$ compared to the control group $(n=8$; figure given at peak height threshold $p_{\text {height }}<0.005$ ). Significant clusters are shown using a $t$ statistic colour scale, which corresponds to the level of significance at the voxel level. The distance between the sections is $1.0 \mathrm{~mm}$ with the position relative to Bregma (positive values for sections anterior to Bregma). Images are in neurological convention

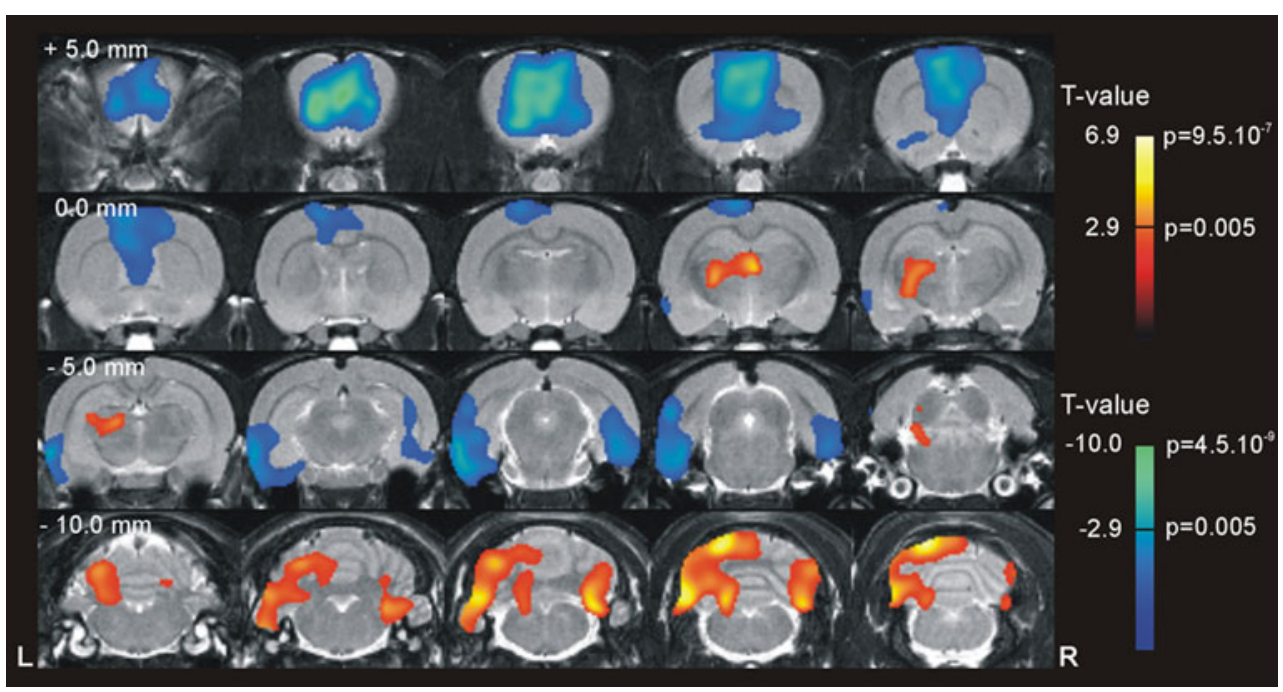

\section{Ex vivo autoradiography}

The above-mentioned changes in CB1 receptor uptake obtained using PET imaging were confirmed by quantitative ex vivo analysis with a similar comparison design. No changes in absolute $\left[{ }^{18} \mathrm{~F}\right] \mathrm{MK}-9470$ uptake were found in the anaesthetized rats as compared to free moving animals. A statistically significant reduction of $9.1 \pm 4.3 \%$ in relative $\left[{ }^{18} \mathrm{~F}\right] \mathrm{MK}-9470$ uptake was observed in the dorsal cortex under isoflurane $(p=0.03)$. This reduction was slightly larger than in vivo. The dorsal cortex defined on autoradiograms encompasses the primary and secondary motor cortex, the cingulate cortex and insular cortex. Ex vivo values for relative $\left[{ }^{18} \mathrm{~F}\right] \mathrm{MK}-9470$ uptake also revealed a significant increase in the cerebellum $(+15.6 \pm 11.4 \%$; $p=$ $0.004)$ and pons $(+11.0 \pm 9.2 \% ; p=0.04)$ under pentobarbital and isoflurane, respectively.

Comparing anaesthetized rats to awake animals yielded similar findings in the dorsal cortex $(-14.4 \pm 4.1 \%, p=$ $0.0002)$ and pons $(+21.5 \pm 11.3 \%, p=0.0005)$ under isoflurane, and in the cerebellum $(+12.5 \pm 11.3 \%, p=0.01)$ under pentobarbital. However, an additional reduction of $9.7 \pm$ $6.2 \%$ in relative $\left[{ }^{18} \mathrm{~F}\right] \mathrm{MK}-9470$ uptake was observed in the dorsal cortex of pentobarbital rats $(p=0.02)$. Absolute or relative $\left[{ }^{18} \mathrm{~F}\right] \mathrm{MK}-9470$ uptake values did not significantly differ between free moving and awake animals.

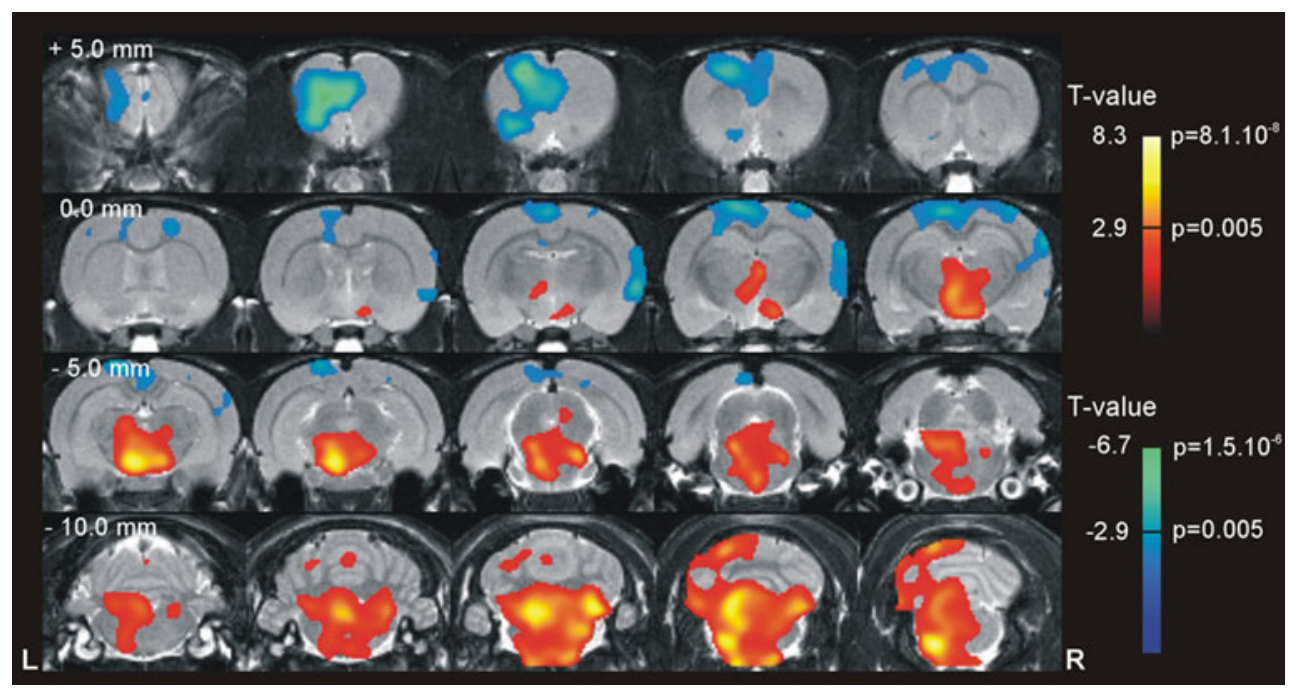

Fig. 5 Coronal brain sections showing overlays on the regions with statistically significantly increased (red) and decreased (blue) relative $\left[{ }^{18} \mathrm{~F}\right] \mathrm{MK}-9470$ binding in the isoflurane group $(n=7)$ compared to the control group $\left(n=8\right.$; figure given at peak height threshold $p_{\text {height }}<$ $0.005)$. Significant clusters are shown using a $t$ statistic colour scale, which corresponds to the level of significance at the voxel level. The distance between the sections is $1.0 \mathrm{~mm}$ with the position relative to Bregma (positive values for sections anterior to Bregma). Images are in neurological convention 
Autoradiography-based relative $\left[{ }^{18} \mathrm{~F}\right] \mathrm{MK}-9470$ uptake values of anaesthetized, free moving and awake rats are given in Table 2.

In vivo and ex vivo relative $\left[{ }^{18} \mathrm{~F}\right] \mathrm{MK}-9470$ data were both correlated in the cerebellum $(r=0.56 ; p<0.008)$, pons $(r=0.57 ; p<0.01)$ and cortex $(r=0.45 ; p<0.04)$, as shown in Fig. 6.

\section{Discussion}

Significant pharmacokinetic influences of anaesthetic agents on the biodistribution and uptake of labelled compounds have been described. Most alterations involve interactions with the target neurotransmitter system or occur by influencing tracer delivery [20]. For in vivo
Table 2 Rat brain relative $\left[{ }^{18} \mathrm{~F}\right]$ MK-9470 uptake values, obtained using ex vivo autoradiography, in different ROIs under isoflurane or pentobarbital anaesthesia and in free moving and awake animals, as well as the regional per cent change in anaesthetized rats as compared to controls
All data are expressed as mean \pm SD

${ }^{*} p<0.05$, one-way ANOVA, Dunnett post hoc test

\begin{tabular}{|c|c|c|c|}
\hline ROI & $\begin{array}{l}\text { Relative }\left[{ }^{18} \mathrm{~F}\right] \mathrm{MK}-9470 \\
\text { binding }\end{array}$ & $\begin{array}{l}\% \text { Change relative to } \\
\text { awake }\end{array}$ & $\begin{array}{l}\% \text { Change relative to free } \\
\text { moving }\end{array}$ \\
\hline \multicolumn{4}{|l|}{ Frontal cortex } \\
\hline Awake & $1.89 \pm 0.23$ & & \\
\hline Free moving & $1.80 \pm 0.22$ & & \\
\hline Isoflurane & $1.86 \pm 0.26$ & $-1.3 \pm 13.6$ & $+6.1 \pm 14.5$ \\
\hline Pentobarbital & $1.80 \pm 0.23$ & $-1.8 \pm 12.2$ & $+2.7 \pm 13.1$ \\
\hline \multicolumn{4}{|l|}{ Dorsal cortex } \\
\hline Awake & $1.64 \pm 0.12$ & & \\
\hline Free moving & $1.55 \pm 0.13$ & & \\
\hline Isoflurane & $1.40 \pm 0.07$ & $-14.4 \pm 4.1 *$ & $-9.1 \pm 4.3^{*}$ \\
\hline Pentobarbital & $1.45 \pm 0.10$ & $-9.7 \pm 6.2^{*}$ & $-5.8 \pm 6.6$ \\
\hline \multicolumn{4}{|l|}{ Ventral cortex } \\
\hline Awake & $1.42 \pm 0.08$ & & \\
\hline Free moving & $1.40 \pm 0.11$ & & \\
\hline Isoflurane & $1.46 \pm 0.40$ & $+2.5 \pm 27.8$ & $+4.8 \pm 28.4$ \\
\hline Pentobarbital & $1.42 \pm 0.10$ & $+3.4 \pm 6.7$ & $+1.7 \pm 6.8$ \\
\hline \multicolumn{4}{|c|}{ Caudate-putamen } \\
\hline Awake & $1.60 \pm 0.10$ & & \\
\hline Free moving & $1.56 \pm 0.17$ & & \\
\hline Isoflurane & $1.58 \pm 0.20$ & $-1.3 \pm 12.6$ & $+1.4 \pm 12.9$ \\
\hline Pentobarbital & $1.73 \pm 0.13$ & $+7.6 \pm 8.2$ & $+11.3 \pm 8.5$ \\
\hline \multicolumn{4}{|c|}{ Anterior hippocampus } \\
\hline Awake & $1.27 \pm 0.08$ & & \\
\hline Free moving & $1.31 \pm 0.08$ & & \\
\hline Isoflurane & $1.29 \pm 0.11$ & $+2.0 \pm 8.4$ & $-1.3 \pm 8.1$ \\
\hline Pentobarbital & $1.29 \pm 0.10$ & $+2.6 \pm 8.1$ & $-1.6 \pm 7.8$ \\
\hline \multicolumn{4}{|c|}{ Posterior hippocampus } \\
\hline Awake & $1.38 \pm 0.12$ & & \\
\hline Free moving & $1.45 \pm 0.14$ & & \\
\hline Isoflurane & $1.45 \pm 0.13$ & $+5.2 \pm 9.2$ & $+1.3 \pm 8.8$ \\
\hline Pentobarbital & $1.29 \pm 0.11$ & $-3.3 \pm 7.8$ & $-10.4 \pm 7.5$ \\
\hline \multicolumn{4}{|l|}{ Pons } \\
\hline Awake & $1.13 \pm 0.08$ & & \\
\hline Free moving & $1.25 \pm 0.12$ & & \\
\hline Isoflurane & $1.37 \pm 0.11$ & $+21.5 \pm 10.1^{*}$ & $+11.0 \pm 9.2^{*}$ \\
\hline Pentobarbital & $1.14 \pm 0.03$ & $+5.1 \pm 2.6$ & $-7.9 \pm 2.4$ \\
\hline \multicolumn{4}{|l|}{ Cerebellum } \\
\hline Awake & $1.49 \pm 0.10$ & & \\
\hline Free moving & $1.45 \pm 0.08$ & & \\
\hline Isoflurane & $1.60 \pm 0.11$ & $+7.3 \pm 7.5$ & $+8.7 \pm 7.6$ \\
\hline Pentobarbital & $1.70 \pm 0.17$ & $+12.5 \pm 11.3 *$ & $+15.6 \pm 11.4^{*}$ \\
\hline
\end{tabular}



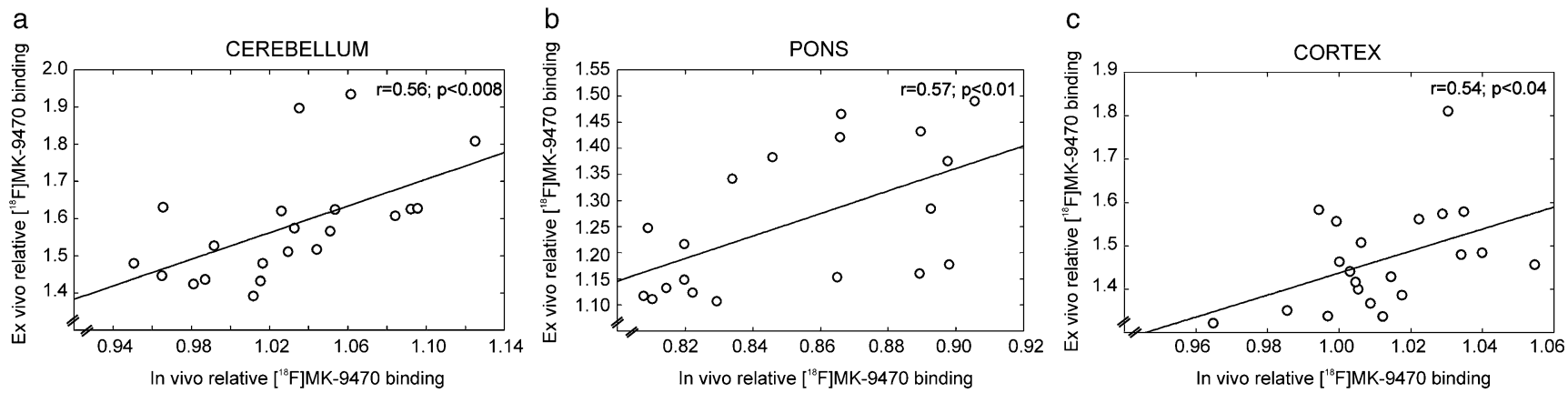

Fig. 6 Relationship of relative $\left[{ }^{18} \mathrm{~F}\right] \mathrm{MK}-9470$ binding values in the cerebellum $(\mathbf{a} r=0.56, p<0.008)$, pons $(\mathbf{b} r=0.57, p<0.01)$ and cortex (c $r=0.45, p<0.04$ ) determined by ex vivo autoradiography and in vivo small animal PET in anaesthetized rats and free moving animals

imaging, such alterations are of importance to assess the translation of studies in small animals under anaesthesia to human or patient findings.

In the present study, we evaluated the effect of two different types of anaesthetics on $\left[{ }^{18} \mathrm{~F}\right] \mathrm{MK}-9470$ uptake in the rat brain using both small animal PET and ex vivo autoradiography. We found that both pentobarbital and isoflurane decrease relative $\left[{ }^{18} \mathrm{~F}\right] \mathrm{MK}-9470$ uptake in cortical regions of the rat brain, whereas relative $\left[{ }^{18} \mathrm{~F}\right] \mathrm{MK}-9470$ uptake values were increased in the cerebellum. The per cent in vivo changes in relative $\left[{ }^{18} \mathrm{~F}\right] \mathrm{MK}-9470$ uptake ranged for both anaesthetics from $-4 \%$ in the sensorimotor cortex to $-13 \%$ in the frontal cortex, while an average increase of $+14 \%$ was found in the cerebellum.

Although the effect of pentobarbital was more pronounced in the cerebral cortex as compared to isoflurane, and isoflurane-induced additional changes in CB1 receptor binding in the pons and medulla oblongata, the otherwise similar distribution results suggest a common mechanism of interference of barbiturates and halogenated ethers with CB1 receptor imaging using $\left[{ }^{18} \mathrm{~F}\right] \mathrm{MK}-9470$. The mechanism of action of the above anaesthetics is still largely unknown. It has been shown that isoflurane, as a volatile anaesthetic, binds to GABA receptors [11], glutamate receptors [12] and glycine receptors [21] and can increase extracellular dopamine concentration through interference with DAT expression [13]. The principle mechanism of action of barbiturates is through their affinity for the $\mathrm{GABA}_{\mathrm{A}}$ receptor [10], but blockage of the AMPA glutamate subtype receptor has also been suggested [22].

Direct interference of pentobarbital and isoflurane with $\left[{ }^{18} \mathrm{~F}\right] \mathrm{MK}-9470$ is unlikely to underlie our findings. To the best of our knowledge, no direct interference has been suggested from structurally related compounds. Besides, extensive in vitro screening of $\left[{ }^{18} \mathrm{~F}\right] \mathrm{MK}-9470$ against more than 100 cerebral receptors and ion channels, among which the GABA and glutamate receptors, yielded no significant off-target activities [14].

Indirect interference with the $\mathrm{CB} 1$ receptor is on the other hand more probable, considering the above-described anaesthetic mechanisms in combination with the modulatory action of the ECS on GABA and glutamate neurotransmission [1]. There are arguments in favour that this may occur rather through the most abundant excitatory neurotransmitter system in the rat brain than through the inhibitory GABAergic system. All published studies on the glutamate receptor univocally demonstrated that both pentobarbital and isoflurane antagonize the AMPA subtype of excitatory glutamate receptors in vitro [22] and in vivo [23]. By contrast, it has long been recognized that pentobarbital can interact directly with $\mathrm{GABA}_{\mathrm{A}}$ receptor channels, but it is less clear that isoflurane behaves similarly. Results from biochemical assays of $\mathrm{Cl}^{-}$uptake and release yielded conflicting results, with some workers finding inhibition of agonist-induced $\mathrm{Cl}^{-}$flux by volatile agents [24] and others reporting enhancement [25, 26]. Also, electrophysiological data on inhibitory postsynaptic currents and potentials have given equivocal findings [27, 28], although enhancement of GABA-induced $\mathrm{Cl}^{-}$currents in neurons from rat hippocampus [11], dorsal root ganglia [29] and nucleus tractus solitarii [30] have been demonstrated at relevant concentrations of volatile anaesthetics using voltage clamp studies.

The interaction between the ECS and the GABAergic and glutamatergic neurotransmitter system is anatomically possible in the observed regions. The density of both GABA and glutamate receptors is higher in the cerebral cortex and cerebellum than in most other parts of the central nervous system [31-33], where they colocalize with CB1 receptors on pyramidal neurons in the cortex and on Purkinje cells in the cerebellum [34]. Moreover, in humans, evidence from functional imaging studies (fMRI, PET, magnetoencephalogram and EEG) suggests that especially the cortex and its connectivity to the thalamus is linked to the loss of consciousness upon anaesthesia (for review see [35]). Involvement of the cerebellum in their central action has less consistently been documented. Schlünzen et al. demonstrated reduced cerebellar neuronal activity upon isoflurane and sevoflurane anaesthesia by means of human CBF PET [36], while others did not observe this [35]. 
Besides altering neurotransmitter systems, anaesthetics may also modify physiological parameters such as body temperature and blood pressure, and subsequently affect physiological macroparameters such as regional cerebral blood flow (rCBF). Changes in $\mathrm{rCBF}$, altering the amount of tracer delivered to the brain and thereby the degree of tracer uptake to CB1 receptors, are, however, less likely to explain our findings. Previous reports described contradictory effects of both anaesthetics on CBF. Isoflurane acts as a potent cerebrovasodilator across species [37, 38], consistent with an increase in CBF upon administration [39]. In contrast, investigations demonstrated grey matter $\mathrm{CBF}$ reductions by pentobarbital and other barbiturates in rats as compared to a variety of control conditions [39, 40]. Moreover, we have found that direct measurements of flow stimulation effects using acetazolamide (Diamox ${ }^{\circledR}$ ), inducing $70 \%$ increases in $\mathrm{CBF}$, induced only slight increases in rat brain $\left[{ }^{18} \mathrm{~F}\right] \mathrm{MK}-9470$ SUV values (unpublished findings). Also in humans, $\left[{ }^{18} \mathrm{~F}\right] \mathrm{MK}-9470 \mathrm{SUV}$ values estimated under blindfolded and visual activation conditions in six subjects indicated that tracer uptake is independent of flow [41].

Correlating both in vivo and ex vivo molecular imaging techniques in the same animal, we found a correspondence between CB1 receptor uptake as measured in vivo by small animal PET and ex vivo by autoradiography in the cerebellum, pons and cortex. Ex vivo relative $\left[{ }^{18} \mathrm{~F}\right] \mathrm{MK}$ 9470 uptake values were in comparison to free moving rats only significantly different in the cortex under isoflurane and in the cerebellum under pentobarbital, while both anaesthetics reached significance in these regions in vivo. This difference, however, fits well with the reported higher inter- and intrasubject variability for 2-D autoradiography [42] (Table 2).

In addition, using only the ex vivo analysis approach, we found no significant differences in absolute and relative $\left[{ }^{18} \mathrm{~F}\right] \mathrm{MK}-9470$ uptake values between free moving rats and awake animals. Nevertheless, an additional reduction in relative $\left[{ }^{18} \mathrm{~F}\right] \mathrm{MK}-9470$ uptake was observed in the dorsal cortex of pentobarbital rats as compared to awake animals (instead of to those that were free moving) (Table 2). From this, a potential effect of the anaesthesia given during tracer injection cannot completely be excluded. Since the per cent in vivo changes in relative $\left[{ }^{18} \mathrm{~F}\right] \mathrm{MK}-9470$ uptake were modest, a slight underestimation may have been made, especially in the cortical regions.

We have used female Wistar rats and it is known that the menstrual cycle may influence receptor expression. Rodríguez de Fonseca et al. demonstrated the existence of subtle fluctuations along the ovarian cycle in $\mathrm{CB} 1$ receptor density and affinity of certain rat brain regions [43]. Also in rats, second-order effects of oestrogen on $\mathrm{GABA}_{\mathrm{A}}$ receptor stimulation have been reported [44], as well as differences of it in the sensitivity to isoflurane [45]. Since our in vivo outcome intersubject variability is small (in the order of $10 \%$ for each group studied) over various phases of the oestrus cycle, it is only a minor potential bias and unlikely to have affected the results of the study.

\section{Conclusion}

In conclusion, this study shows that two common general anaesthetics have similar regional effects on the in vivo CB1 receptor binding of $\left[{ }^{18} \mathrm{~F}\right] \mathrm{MK}-9470$, particularly in the cerebellum and the cortical regions of the rat brain. These alterations were modest, especially in the cortical regions. They suggest no preference for one anaesthetic for in vivo CB1 receptor imaging using $\left[{ }^{18} \mathrm{~F}\right] \mathrm{MK}-9470$. Nevertheless, compared to pentobarbital, isoflurane has more favourable characteristics (minimally metabolized, faster elimination and less chance of respiratory depression).

Acknowledgements The authors thank the Leuven PET radiopharmacy team for $\left[{ }^{18} \mathrm{~F}\right] \mathrm{MK}-9470$ production and Merck \& Co., Inc. for their availability of the $\left[{ }^{18} \mathrm{~F}\right] \mathrm{MK}-9470$ precursor. Financial support of the Research Council of the Katholieke Universiteit Leuven (OT/05/58), the Fund for Scientific Research, Flanders, Belgium (FWO/G.0548.06) and the Institute for the Promotion of Innovation by Science and Technology in Flanders (SBO50151) is gratefully acknowledged. This work is also supported by MoSAIC, the K.U. Leuven Molecular Small Animal Imaging Center (KUL EF/05/08). KVL is a Senior Clinical Investigator of the Flemish Fund of Scientific Research. Part of this work is performed under the European Commission FP6 project Diagnostic Molecular Imaging (DIMI), LSHB-CT-2005-512146.

Conflicts of interest None.

\section{References}

1. Di Marzo V, Melck D, Bisogno T, De Petrocellis L. Endocannabinoids: endogenous cannabinoid receptor ligands with neuromodulatory action. Trends Neurosci 1998;21:521-8.

2. Van Laere K. In vivo imaging of the endocannabinoid system: a novel window to a central modulatory mechanism in humans. Eur J Nucl Med Mol Imaging 2007;34:1719-26.

3. Wilson RI, Nicoll RA. Endocannabinoid signaling in the brain. Science 2002;296:678-82.

4. Bahr BA, Karanian DA, Makanji SS, Makriyannis A. Targeting the endocannabinoid system in treating brain disorders. Expert Opin Investig Drugs 2006;15:351-65.

5. Cherry SR, Gambhir SS. Use of positron emission tomography in animal research. ILAR J 2001;42:219-32.

6. Momosaki S, Hatano K, Kawasumi Y, Kato T, Hosoi R, Kobayashi K, et al. Rat-PET study without anesthesia: anesthetics modify the dopamine D1 receptor binding in rat brain. Synapse 2004;54:207-13.

7. Votaw JR, Byas-Smith MG, Voll R, Halkar R, Goodman MM. Isoflurane alters the amount of dopamine transporter expressed on the plasma membrane in humans. Anesthesiology 2004;101: $1128-35$.

8. Kobayashi $\mathrm{K}$, Inoue $\mathrm{O}$, Watanabe $\mathrm{Y}$, Onoe $\mathrm{H}$, Långström $\mathrm{B}$. Difference in response of D2 receptor binding between $11 \mathrm{C}-\mathrm{N}$ - 
methylspiperone and 11C-raclopride against anesthetics in rhesus monkey brain. J Neural Transm Gen Sect 1995;100:147-51.

9. Toyama H, Ichise M, Liow JS, Modell KJ, Vines DC, Esaki T, et al. Absolute quantification of regional cerebral glucose utilization in mice by $18 \mathrm{~F}-\mathrm{FDG}$ small animal PET scanning and 2-14C-DG autoradiography. J Nucl Med 2004;45:1398-405.

10. Zeller A, Arras M, Jurd R, Rudolph U. Identification of a molecular target mediating the general anesthetic actions of pentobarbital. Mol Pharmacol 2007;71:852-9.

11. Jones MV, Brooks PA, Harrison NL. Enhancement of gammaaminobutyric acid-activated Cl- currents in cultured rat hippocampal neurones by three volatile anaesthetics. J Physiol 1992;449:279-93.

12. Yang J, Zorumski CF. Effects of isoflurane on N-methyl-Daspartate gated ion channels in cultured rat hippocampal neurons. Ann N Y Acad Sci 1991;625:287-9.

13. Votaw J, Byas-Smith M, Hua J, Voll R, Martarello L, Levey AI, et al. Interaction of isoflurane with the dopamine transporter. Anesthesiology 2003;98:404-11.

14. Burns HD, Van Laere K, Sanabria-Bohórquez S, Hamill TG, Bormans G, Eng WS, et al. [18F]MK-9470, a positron emission tomography (PET) tracer for in vivo human PET brain imaging of the cannabinoid-1 receptor. Proc Natl Acad Sci U S A 2007; 104:9800-5.

15. Goffin K, Bormans G, Casteels C, Bosier B, Lambert DM, Grachev ID, et al. An in vivo [(18)F]MK-9470 microPET study of type 1 cannabinoid receptor binding in Wistar rats after chronic administration of valproate and levetiracetam. Neuropharmacology 2008;54:1103-6.

16. Casteels C, Vermaelen P, Nuyts J, Van Der Linden A, Baekelandt $\mathrm{V}$, Mortelmans L, et al. Construction and evaluation of multitracer small-animal PET probabilistic atlases for voxel-based functional mapping of the rat brain. J Nucl Med 2006;47:1858-66.

17. van Kuyck K, Casteels C, Vermaelen P, Bormans G, Nuttin B, Van Laere K. Motor- and food-related metabolic cerebral changes in the activity-based rat model for anorexia nervosa: a voxel-based microPET study. Neuroimage 2007;35:214-21.

18. Herkenham M, Lynn AB, Little MD, Johnson MR, Melvin LS, de Costa BR, et al. Cannabinoid receptor localization in brain. Proc Natl Acad Sci U S A 1990;87:1932-6.

19. Paxinos G, Watson C. The rat brain in stereotaxic coordinates. New York: Academic; 1998.

20. Hildebrandt IJ, Su H, Weber WA. Anesthesia and other considerations for in vivo imaging of small animals. ILAR J 2008;49:17-26.

21. Zhang Y, Laster MJ, Hara K, Harris RA, Eger EI 2nd, Stabernack $\mathrm{CR}$, et al. Glycine receptors mediate part of the immobility produced by inhaled anesthetics. Anesth Analg 2003;96:97-101.

22. Carlà V, Moroni F. General anaesthetics inhibit the responses induced by glutamate receptor agonists in the mouse cortex. Neurosci Lett 1992;146:21-4.

23. Kimbro JR, Kelly PJ, Drummond JC, Cole DJ, Patel PM. Isoflurane and pentobarbital reduce AMPA toxicity in vivo in the rat cerebral cortex. Anesthesiology 2000;92:806-12.

24. Moody EJ, Suzdak PD, Paul SM, Skolnick P. Modulation of the benzodiazepine/gamma-aminobutyric acid receptor chloride channel complex by inhalation anesthetics. J Neurochem 1988; 51:1386-93.

25. Huidobro-Toro JP, Bleck V, Allan AM, Harris RA. Neurochemical actions of anesthetic drugs on the gamma-aminobutyric acid receptorchloride channel complex. J Pharmacol Exp Ther 1987;242:963-9.

26. Longoni B, Demontis GC, Olsen RW. Enhancement of gammaaminobutyric acidA receptor function and binding by the volatile anesthetic halothane. J Pharmacol Exp Ther 1993;266:153-9.
27. Mody I, Tanelian DL, MacIver MB. Halothane enhances tonic neuronal inhibition by elevating intracellular calcium. Brain Res 1991;538:319-23.

28. Gage PW, Robertson B. Prolongation of inhibitory postsynaptic currents by pentobarbitone, halothane and ketamine in CA1 pyramidal cells in rat hippocampus. Br J Pharmacol 1985;85: 675-81.

29. Nakahiro M, Yeh JZ, Brunner E, Narahashi T. General anesthetics modulate GABA receptor channel complex in rat dorsal root ganglion neurons. FASEB J 1989;3:1850-4.

30. Wakamori M, Ikemoto Y, Akaike N. Effects of two volatile anesthetics and a volatile convulsant on the excitatory and inhibitory amino acid responses in dissociated CNS neurons of the rat. J Neurophysiol 1991;66:2014-21.

31. Gutiérrez A, Khan ZU, De Blas AL. Immunocytochemical localization of gamma 2 short and gamma 2 long subunits of the GABAA receptor in the rat brain. J Neurosci 1994;14:716879.

32. Petralia RS, Wenthold RJ. Light and electron immunocytochemical localization of AMPA-selective glutamate receptors in the rat brain. J Comp Neurol 1992;318:329-54.

33. Martin LJ, Blackstone CD, Huganir RL, Price DL. Cellular localization of a metabotropic glutamate receptor in rat brain. Neuron 1992;9:259-70.

34. Moldrich G, Wenger T. Localization of the CB1 cannabinoid receptor in the rat brain. An immunohistochemical study. Peptides 2000;21:1735-42.

35. Ramani R, Wardhan R. Understanding anesthesia through functional imaging. Curr Opin Anaesthesiol 2008;21:530-6.

36. Schlünzen L, Cold GE, Rasmussen M, Vafaee MS. Effects of dose-dependent levels of isoflurane on cerebral blood flow in healthy subjects studied using positron emission tomography. Acta Anaesthesiol Scand 2006;50:306-12.

37. Hansen TD, Warner DS, Todd MM, Vust LJ, Trawick DC. Distribution of cerebral blood flow during halothane versus isoflurane anesthesia in rats. Anesthesiology 1988;69:332-7.

38. Matta BF, Heath KJ, Tipping K, Summors AC. Direct cerebral vasodilatory effects of sevoflurane and isoflurane. Anesthesiology 1999;91:677-80.

39. Hendrich KS, Kochanek PM, Melick JA, Schiding JK, Statler $\mathrm{KD}$, Williams DS, et al. Cerebral perfusion during anesthesia with fentanyl, isoflurane, or pentobarbital in normal rats studied by arterial spin-labeled MRI. Magn Reson Med 2001;46:202-6.

40. Todd MM, Weeks J. Comparative effects of propofol, pentobarbital, and isoflurane on cerebral blood flow and blood volume. J Neurosurg Anesthesiol 1996;8:296-303.

41. Sanabria-Bohórquez SM, Hamill TG, Goffin K, De Lepeleire I, Bormans G, Burns HD, et al. Kinetic analysis of the cannabinoid1 receptor PET tracer [(18)F]MK-9470 in human brain. Eur J Nucl Med Mol Imaging, in press. 2009.

42. Sugiura M, Kawashima R, Sadato N, Senda M, Kanno I, Oda K, et al. Anatomic validation of spatial normalization methods for PET. J Nucl Med 1999;40:317-22.

43. Rodríguez de Fonseca F, Cebeira M, Ramos JA, Martín M, Fernández-Ruiz JJ. Cannabinoid receptors in rat brain areas: sexual differences, fluctuations during estrous cycle and changes after gonadectomy and sex steroid replacement. Life Sci 1994;54:159-70.

44. Westerling P, Lindgren S, Meyerson B. Functional changes in GABAA receptor stimulation during the oestrous cycle of the rat. Br J Pharmacol 1991;103:1580-4.

45. Flood P, Daniel D. Pronociceptive actions of isoflurane: a protective role for estrogen. Anesthesiology 2003;99:476-9. 